\title{
O Processo de Separação-Individuação em Adolescentes do Sexo Masculino na Transição para a Paternidade
}

\author{
The Process of Separation-Individuation in Adolescents \\ During Transition to Fatherhood
}

\author{
Daniela Centenaro Levandowski*, Cesar Augusto Piccinini \& Rita de Cássia Sobreira Lopes \\ Universidade Federal do Rio Grande do Sul, Instituto de Psicologia
}

\begin{abstract}
Resumo
O presente estudo investigou o processo de separação-individuação de adolescentes do sexo masculino na transição para a paternidade. Os participantes foram três adolescentes, com 16 a 18 anos de idade no início da coleta de dados, residentes em Porto Alegre. Foi utilizado um delineamento de estudo de caso coletivo, de caráter longitudinal, para avaliar tal aspecto junto aos adolescentes no terceiro trimestre de gestação, terceiro mês, primeiro e segundo ano do bebê. Os relatos dos participantes foram analisados através de análise de conteúdo qualitativa, buscando investigar indicadores da segunda (Blos, 1996) e terceira (Colarusso, 1990) individuação. Foi possível constatar características das duas fases desse processo, especialmente no segundo ano do bebê, indicando que a paternidade, apesar de dificultar a vivência de algumas tarefas específicas da adolescência, trouxe alguns avanços no aspecto emocional.

Palavras-chave: Adolescência; Paternidade; Processo de separação-individuação.
\end{abstract}

\begin{abstract}
The present study aimed at investigating the separation-individuation process in male adolescents during transition period to fatherhood. Three young fathers, aged between 16 and 18 years old in the beginning of data collection, living in Porto Alegre, took part in the study. To evaluate this process, the study used a collective-case design, of a longitudinal character, which comprised four phases: third quarter of pregnancy, the baby's third month, his/her first and second year. The participants' answers were analyzed through qualitative content analysis, looking for indicators of the second (Blos, 1996) and the third individuation (Colarusso, 1990). It was possible to verify characteristics of the second individuation in the young fathers, as well as of the third, especially in the child's second year of life, indicating that fatherhood brought some advances for emotional development is concerned, even though it also made some tasks of adolescence more difficult to be achieved.

Keywords: Adolescence; Fatherhood; Separation-individuation process.
\end{abstract}

Apesar de sua relevância social, a transição para a paternidade na adolescência tem sido ainda pouco focalizada como tema de estudo no meio acadêmico nacional. Embora seja possível encontrar algumas publicações sobre essa temática (ex. Fonseca, 1997; Levandowski, 2001; Levandowski \& Piccinini, 2002, 2004, 2006; Medrado \& Lyra, 1999; E. Trindade \& Bruns, 1999; Z. A. Trindade $\&$ Menandro, 2002), a maior parte dos estudos nacionais versa sobre a gestação e a maternidade a partir da

* Endereço para correspondência: Fundação Universidade Federal de Ciências da Saúde de Porto Alegre, Departamento de Psicologia, Rua Sarmento Leite, 245, Sala 207, Centro, Porto Alegre, RS, Brasil, CEP90050-170. Tel.: (51) 3303 8826; Fax: (51)3303 8810. E-mail: d.cl@ terra.com.br O presente artigo é baseado em parte da Tese de Doutorado da primeira autora, intitulada "A Transição para a Parentalidade e a Relação de Casal de Adolescentes", apresentada ao Programa de Pós-Graduação em Psicologia da Universidade Federal do Rio Grande do Sul, sob orientação do segundo autor e co-orientação da terceira autora. perspectiva da adolescente (ex. Chalem et al., 2007; Folle \& Geib, 2004; Magalhães et al., 2006; McCallum \& Reis, 2006; Silva \& Salomão, 2003).

Contudo, dado o expressivo número de adolescentes que atualmente passam pela situação inesperada de gestar e cuidar de um bebê $\hat{e}^{1}$, cujos parceiros muitas vezes são também adolescentes, é importante que seja dada maior atenção ao pai adolescente. Nesse sentido, o presente estudo teve por objetivo investigar o processo de separação-individuação em adolescentes do sexo masculino na transição para a paternidade.

A escolha por essa perspectiva teórica se deu em função da escassez de uma teoria de base evolutiva/desenvol-
${ }^{1}$ As Estatísticas do Registro Civil de 2005 (Instituto Brasi-
leiro de Geografia e Estatística [IBGE]) informam uma taxa
de $20,7 \%$ de registros de nascimentos de bebês de mães até
20 anos no Brasil, sendo os maiores índices encontrados
nas regiões Norte e Nordeste do país. 
vimental em diversos estudos nacionais e internacionais localizados sobre o tema paternidade na adolescência (Levandowski, 2005; Levandowski \& Piccinini, 2004). Na verdade, não foi localizado nenhum trabalho que abordasse a paternidade na adolescência sob esse enfoque. Cabe, então, apresentar brevemente os seus principais pressupostos.

Mahler et al. (Mahler, 1982; Mahler, Pine, \& Bergman, 2002) postularam a existência de um processo normal de separação-individuação na infância, também chamado de primeira individuação. Tal processo, que envolve a separação e a individuação do bebê em relação à mãe, seria o primeiro e decisivo pré-requisito para o desenvolvimento e a manutenção de um senso de identidade, uma auto-imagem seguramente individualizada e diferenciada de si mesmo.

Separação e individuação são considerados dois processos estruturais diferentes e complementares (Mahler, 1982; Mahler et al., 2002). O primeiro significa a saída da criança da fusão simbiótica com a mãe, visando à aquisição intrapsíquica de um sentido de desligamento da mãe e do mundo em geral (sentimento de ser um indivíduo separado). Já o segundo indica a evolução da autonomia psíquica, com a criança assumindo suas características individuais. Assim, para Mahler et al. (2002), tal processo levaria ao nascimento psicológico do indivíduo, a partir de algumas etapas específicas. A primeira individuação iniciaria a partir do quarto ou quinto mês de vida e estaria sendo finalizada por volta do $36^{\circ}$. mês.

Uma segunda fase desse processo, proposta por Blos (1994, 1996), denominada segunda individuação, ocorreria na adolescência. Para o autor, devido à reedição do Complexo de Édipo nesse momento, o jovem revive suas relações primitivas com seus pais, ao mesmo tempo em que necessita realizar um trabalho psíquico de separação e diferenciação das imagens internalizadas dos mesmos. Assim, na infância o desligamento da mãe era de cunho físico, a partir da internalização de uma imagem da mesma; na adolescência, por sua vez, acontece o desligamento destes objetos internalizados, a fim de que o jovem possa seguir adiante, descobrindo outros objetos que serão amados ou odiados, o que possibilitaria a formação de seu próprio grupo familiar.

Tal processo de decatexia das imagens internalizadas dos pais pode levar ao engrandecimento do self, sendo o amor pelos pais substituído pelo amor a si mesmo ou pela própria perfeição potencial (Blos, 1996). De modo semelhante, a libido objetal livre pode ser dirigida para novos objetos de amor heterossexual. Situações como revolta, oposição e negativismo intenso, rompimento brusco com a família ou distanciamento físico denotam, segundo Blos (1996), manobras defensivas do adolescente, ao invés da vivência adequada desse processo. Caso o adolescente se desenvolva bem, isto favorecerá o amadurecimento do ego, pela capacidade de relacionamentos mais maduros, pela evitação de um retorno posterior à infância e pela possibilidade do surgimento de novas funções autônomas. Caso contrário, haverá o impedimento, retardo ou restrição da descoberta de objetos extra-familiares.

Após a resolução deste processo, o jovem passaria a ter a possibilidade de vivenciar, na idade adulta jovem, a terceira individuação, postulada por Colarusso (1990). Nessa etapa, o adulto jovem se depararia com uma solidão intrapsíquica normativa, devido ao fato de não poder mais se apoiar nos pais para orientação, manutenção e direção, em função da modificação e do enfraquecimento das suas representações intrapsíquicas, ao mesmo tempo em que ainda não estaria envolvido com novos vínculos intensos que os substituissem. Essa solidão, então, levaria o adulto jovem ao estabelecimento de uma nova família. $\mathrm{O}$ vínculo objetal com o próprio filho e o contínuo envolvimento heterossexual com um cônjuge favoreceriam uma maior elaboração do self e diferenciação dos objetos.

Assim, a parentalidade se constitui na questão central da terceira individuação, por ser a extensão natural da continuidade biogenética na qual ocorreram os processos anteriores (Colarusso, 1990). O adulto jovem usa sua maturidade física e sua crescente capacidade de intimidade para criar uma nova vida e assumir o papel parental no processo de separação-individuação. Dessa forma, a parentalidade permitiria a reelaboração de temas e relações infantis, pois, como pais, os adultos reeditam com o filho a situação de intimidade que tiveram com seus próprios pais na infância, e assim reconhecem no que se parecem com eles (na capacidade de cuidar-se, de amar física e emocionalmente e de procriar) e também no que se diferenciam deles. Tal situação estimula a individuação e, ao mesmo tempo, reforça a continuidade e a conexão entre as gerações. A individuação também seria reforçada pela habilidade de dar aos pais um neto, sua continuidade genética, o que traz prestígio e poder frente aos mesmos.

Essas concepções teóricas do processo de separaçãoindividuação indicam a complexidade desse fenômeno, bem como suas peculiaridades ao longo das diferentes etapas de desenvolvimento. Nesse sentido, o presente estudo investigou tal processo em adolescentes na transição para a paternidade, uma vez que, nessa situação, se sobrepõem questões ligadas à segunda e à terceira individuação, em particular, a separação psicológica dos pais versus a aproximação aos mesmos em função do desempenho do papel paterno e da nova relação com o bebê.

\section{Método}

\section{Participantes}

Participaram do estudo três adolescentes do sexo masculino, com 16 a 18 anos de idade no início da coleta de dados, residentes em Porto Alegre, RS, dois de nível socioeconômico baixo e um de nível socioeconômico médio. Eles foram selecionados da amostra do Estudo Longitudinal de Porto Alegre: Da Gestação à Escola (Piccinini, Tudge, Lopes, \& Sperb, 1998), que recebeu 
aprovação do Comitê de Ética do Hospital de Clínicas de Porto Alegre (Processo n. 98293, de 30 de outubro de 1998).

Como parte do projeto longitudinal, diversos pesquisadores acompanharam grupos específicos de casais. Em função dos interesses da primeira autora do presente artigo, coube-lhe acompanhar os futuros pais e mães adolescentes. Dentre os 11 casais adolescentes acompanhados, os três pais adolescentes foram selecionados para esse estudo com base nos seguintes critérios: idade inicial inferior a 18 anos, realização de todas as etapas de coleta de dados e manutenção da relação de casal, com coabitação, desde a gestação até o segundo ano do bebê.

O primeiro participante, aqui denominado Cléber, tinha 18 anos no início da coleta de dados e 05 anos de escolarização formal, trabalhava como pedreiro e era de nível socioeconômico baixo. Já o segundo participante, Miguel, tinha 17 anos de idade, 10 anos de escolarização formal, estudava e era de nível socioeconômico médio. O terceiro participante, Dante, tinha 16 anos, 04 anos de escolarização formal, trabalhava como jardineiro e era de nível socioeconômico baixo. Todos coabitavam com suas parceiras (Cléber na casa da mãe da parceira, Dante na casa dos pais da parceira e Miguel em sua casa) ${ }^{2}$.

\section{Delineamento, Procedimentos e Instrumentos}

Foi utilizado um delineamento de estudo de caso coletivo (Stake, 1994) de caráter longitudinal, para investigar o processo de separação-individuação de adolescentes na transição para a paternidade. Cada caso foi investigado em quatro momentos: terceiro trimestre da gestação, terceiro mês, primeiro e segundo ano do bebê.

Conforme procedimento estipulado no projeto longitudinal, do qual deriva o presente estudo, a primeira autora do presente artigo compareceu a grupos de gestantes para explicar os objetivos da pesquisa e os procedimentos que seriam realizados. Aquelas que desejavam participar, preenchiam a Entrevista de Contato Inicial (Grupo de Pesquisa em Infância, Desenvolvimento e Psicopatologia [GIDEP], 1998a), uma ficha usada para coletar dados demográficos e verificar os casais que atendiam os critérios de seleção dos participantes (estar esperando o primeiro filho, no terceiro trimestre da gestação e não apresentar complicações físicas durante a gestação). Estes casais foram contatados posteriormente por telefone, para se explicitar os objetivos da pesquisa e verificar a disponibilidade para a participação.

Após a aceitação do convite pelos dois membros do casal, era marcada uma visita à sua residência, entre o sétimo e o oitavo mês de gestação. Neste dia, ambos as-

${ }^{2}$ Dados desses participantes também foram utilizados em outros artigos derivados da mesma Tese, que investigou a transição para a parentalidade e a relação de casal de adolescentes (Levandowski, 2005), no caso, Individualidade e conjugalidade na relação de casal de adolescentes (Levandowski, Piccinini \& Lopes, no prelo). sinavam um Termo de Consentimento Livre e Esclarecido (GIDEP, 1998b) e, num segundo momento, eram solicitados a preencher a Entrevista de Dados Demográficos do Casal (GIDEP, 1998c), uma ficha usada para complementar os dados demográficos obtidos inicialmente. Em um terceiro momento, foi realizada com o futuro pai adolescente uma entrevista semi-estruturada - Entrevista sobre a Gestação e as Expectativas do Futuro Pai (GIDEP, 1998c).

Na segunda fase ${ }^{3}$, aos três meses de vida do bebê, era feito um novo contato telefônico e agendada uma visita à residência dos participantes. Nessa ocasião, os pais foram entrevistados individualmente (Entrevista sobre a Experiência da Paternidade: Terceiro Mês do Bebê, GIDEP, 1999). Na terceira fase, no primeiro ano do bebê, os participantes foram novamente contatados e foi marcada uma visita à Sala de Brinquedos, no Instituto de Psicologia da UFRGS, quando foi realizada individualmente a Entrevista com o Pai sobre o Desenvolvimento do Bebê: Primeiro Ano do Bebê (GIDEP, 2000), também de caráter semi-estruturado. Na quarta e última fase, no segundo ano de vida do bebê, repetiu-se o mesmo procedimento, tendo sido realizada individualmente a Entrevista com o Paila Mãe sobre o Desenvolvimento do Bebê: Segundo Ano do Bebê (GIDEP, 2001). Todas as entrevistas foram gravadas e transcritas literalmente para análise.

\section{Resultados e Discussão}

Análise de conteúdo qualitativa (Bardin, 1977; Laville \& Dionne, 1999) das entrevistas foi utilizada para investigar o processo de separação-individuação dos adolescentes na transição para a paternidade, da gestação até o segundo ano de vida do bebê. Foram realizadas repetidas leituras das entrevistas, buscando identificar informações que permitissem a compreensão desse processo nas etapas examinadas. Para tanto, foram consideradas as seguintes temáticas, baseadas na literatura (Blos, 1996; Colarusso, 1990): relacionamento com o próprio pai na infância e atualmente, modelos paternos a serem seguidos e evitados, características de um "bom pai", expectativas em relação ao desempenho do papel paterno e à criação do filho, percepção pessoal acerca do desempenho do papel paterno, atividades e tarefas desempenhadas, mudanças pessoais e sentimentos despertados pela paternidade.

A partir da identificação desses temas nas entrevistas, elaborou-se um relato longitudinal de cada caso. Após a elaboração dos relatos dos casos, buscou-se investigar as semelhanças e particularidades entre os casos. Com base neste procedimento, apresenta-se a seguir uma breve

${ }^{3}$ Em todas as fases, outros instrumentos foram também aplicados, conforme descrito por Piccinini et al. (1998), mas não foram analisados no presente estudo. 
descrição de cada caso ao longo dos quatro momentos investigados ${ }^{4}$, seguida de um entendimento dinâmico longitudinal do processo de separação-individuação. Após a exposição dos três casos, são discutidas as semelhanças entre eles.

\section{Caso 1: Cléber}

\section{Gestação}

Cléber tornou-se pai de um menino aos 18 anos, de forma inesperada. Namorava Daiane (18 anos) há alguns meses quando isso aconteceu pelo não uso do preservativo. Eles se conheciam desde a infância, pois moravam no mesmo bairro. Ficaram juntos na festa de aniversário de uma amiga. Passaram algum tempo sem contato, pois ele $\log$ o "ficou" com outra menina. Como esse relacionamento terminou, Daiane procurou-o novamente. Um mês depois ele reapareceu e desde então estavam juntos. Quando da descoberta da gestação, passou a morar na casa da mãe de Daiane. Cléber disse ter ficado "meio assustado" com a notícia, pois queria ter um filho, mas não naquele momento. Ao mesmo tempo, contou com felicidade a realização do exame e a confirmação da gravidez. Desde o início quis assumir a gravidez.

Relatou se imaginar "um pai legal pro meu filho". Imaginava estar "toda hora" perto do filho, dando atenção e carinho, cuidando e passeando com ele. Imaginava ainda dar "bastante força para ele, que nem a minha mãe deu força para mim". Não referiu nenhum modelo paterno a ser seguido, mencionando como modelo a ser evitado um pai que não gosta da criança e nem da esposa e que não dá atenção, pois quer ter o filho sempre perto e formar uma família. Para ele, um bom pai "dá atenção pro filho, aonde o filho quiser ir tu leva, o que ele quiser tu dá, fazer as coisas que ele quiser, tudinho direitinho". Sobre o relacionamento com o pai, Cléber relatou que nem chegou a conhecê-lo. Disse que a mãe exerceu os dois papéis, auxiliada pela sua própria mãe.

\section{Terceiro Mês do Bebê}

Cléber referiu estar gostando de ser pai: "tô me sentindo bem, tô gostando". Acrescentou que a paternidade o havia tirado da rua: "eu tô mais caseiro, mas perto dele, tô dando mais atenção pra ele crescer do meu lado, não vou abandonar ela nem ele!". Considerava que a paternidade estava sendo menos difícil do que imaginava: "não tô achando difícil, eu gosto dele e dela, eu acho legal até, ser pai tá sendo legal". Não referiu dificuldade no desempenho do papel paterno. Descreveu-se como um pai "coruja", que ficava sempre pensando no filho, mes-

\footnotetext{
${ }^{4} \mathrm{Na}$ Tese de Doutorado, da qual deriva o presente estudo, são apresentados detalhes de cada um dos casos, que, por razões de espaço, não puderam ser destacados aqui. Pela mesma razão, os trechos das entrevistas transcritos aqui foram por vezes editados, sem que isso afetasse o seu sentido original.
}

mo enquanto estava trabalhando. Nesse momento, o casal já estava morando em uma casa própria, construída por ele para a nova família.

\section{Primeiro Ano do Bebê}

Cléber novamente comentou que a paternidade estava sendo mais fácil do que imaginava: "eu tô me sentindo legal mesmo com ele, sempre brincando, sempre fazendo as coisas com ele. Quando eu saio, eu faço tudo ligeiro pra ir pra casa brincar com ele". Descreveu-se novamente como um pai "coruja", um bom pai, pois estava sempre cuidando, "fazendo as coisas pra ele [o filho] se sentir legal, sempre em volta dele, o que eu posso fazer por ele, eu faço".

\section{Segundo Ano do Bebê}

Cléber referiu como positiva a experiência de ser pai: "é tri, sempre gostei de ver os outros [pais], com outras crianças. Eu sempre tava junto com criança”. Não sentia nenhuma dificuldade na criação do filho: "ele nunca deu trabalho pra nós". Considerou-se novamente um bom pai, por estar sempre com o filho, ajudando, protegendo e conversando com ele. Não gostava de se afastar do menino nem para trabalhar. Às vezes até chegava atrasado no serviço, para não deixá-lo chorando. Referiu como modelo paterno a ser seguido pessoas da sua idade: "eu acho tri guri [jovem] que cuida dos filhos, eu sempre curto. Às vezes eu olho, 'Bah, uns guri novo, assim, com carrinho e filho no colo!', eu fico olhando, 'Bah, que legal mesmo!'. Já como modelo a ser evitado, mencionou um pai que "não cuida da criança. Mas sempre tento não fazer, tento sempre evitar ter contato com eles [com outros pais que não cuidam], entendeu?". Pretendia ser um bom pai para o menino: "quando ele é pequeno, pra não sentir algum receio de mim quando crescer, pra ele ter alguma coisa pra ele. Quando ele tiver o serviço dele, a casa dele, a mulher dele, pra ele vir sempre me visitar e falar 'Não, o meu pai é superlegal, sempre me cuidou do jeito certinho, sempre me deu uma educação legal'; pra ele ensinar os filhos dele quando ele crescer, a mesma coisa que eu fiz com ele, entendeu?".

\section{Separação-Individuação na Transição para a Paternidade}

Cléber demonstrou uma aceitação da gravidez e da paternidade, processo que foi marcado por sua grande participação na criação do filho. As suas falas iniciais revelaram uma certa dificuldade de se pensar como pai, talvez pela falta de um modelo paterno a ser seguido. De fato, seu pai serviu como um modelo a ser evitado, ao qual ele já imaginava se opor durante a gravidez, o que foi confirmado a partir do nascimento da criança. Com isso, apresenta uma postura de afirmação de diferença em relação ao próprio pai (Blos, 1996), na tentativa de reparar sua história de falta (Szejer \& Stewart, 1997). 
Assim, contrariamente à sua vivência de ausência em relação à figura paterna, Cléber enfatizou sua participação durante o exercício da paternidade. Nesse sentido, talvez pela presença feminina predominante na sua criação (mãe e avó materna), muitas vezes demonstrava uma postura cuidadora, tradicionalmente feminina ( $\mathrm{Z}$. A. Trindade, 1993), assumindo o filho e a casa. Ao mesmo tempo, chamou a atenção o fato de Cléber não expressar ambivalência ou frustração com a paternidade, $o$ que, conforme Costa e Katz (1992), seria esperado, uma vez que o nascimento pode despertar sentimentos primitivos, conflituosos, contraditórios e ambivalentes nos pais, em particular na relação com o filho.

\section{Caso 2: Miguel}

\section{Gestação}

Miguel e Adriane se conheceram e ficaram juntos em uma festa de aniversário do filho de um vizinho dela. Porém, como Miguel tinha namorada, por seis meses se encontraram esporadicamente, até ele terminar o namoro e ficar somente com ela. Desde então, "foi um grude só", pois passavam todos os dias juntos. Depois de um ano, ela engravidou de uma menina, aos 16 anos, de forma não planejada. Segundo Miguel, quando Adriane iniciou o uso de pílula anticoncepcional, no dia em que ela esqueceu de tomá-la, eles tiveram relação sexual. Sua reação inicial à notícia da gravidez foi de felicidade, "até porque eu não tenho pai e quero descontar essa coisa de eu não ter tido pai, eu quero ter, ser o pai que eu nunca tive, entendeu?". Segundo Miguel, a única mudança decorrente da gravidez havia sido "atrasar um pouco os planos que a gente tinha de fazer faculdade, essa coisarada toda!”.

Esperava ser um pai muito presente, auxiliando e ensinando várias coisas à filha; "eu espero que ela não chore no meu colo, porque senão eu vou ficar desesperado! Eu vou achar que ela não gosta de mim”. Esperava ainda que ela não passasse pelas mesmas dificuldades que ele havia passado em função da ausência do pai. Tinha a intenção de estar "sempre em cima, não quero saber, tudo o que eu puder fazer, eu vou fazer". Não gostaria de proibi-la de fazer coisas, e sim aconselhá-la, porque "sempre tem aquela curiosidade de adolescente".

Miguel confessou não ter conhecido seu pai e não comentou nada sobre o relacionamento com sua mãe na infância. Citou como modelo paterno a ser seguido o pai de um amigo de infância, por ser "engraçado; com ele tem a hora de brincar e de se preocupar, 'Vai estudar, tu vai fazer isso, tu vai fazer aquilo'; ele é super gente fina!". Como modelo a ser evitado, citou o pai da namorada, "ele se acha autoritário, mas ele não tem autoridade sobre os filhos, ele tá sempre pegando no pé de alguém, tá sempre arrumando alguma coisa. Eu não acho nada legal uma pessoa ser alcoólatra, ser viciado em alguma coisa". Para Miguel, um bom pai seria compa- nheiro, estaria sempre ao lado do filho, daria apoio, seria "não só um pai, mas uma pessoa amiga".

\section{Terceiro Mês do Bebê}

Nesse momento, Miguel, sua namorada e sua filha estavam morando na casa da mãe dele. Ele considerava a paternidade uma experiência "diferente, a responsabilidade é bem maior do que antes, porque agora, mais do que nunca, eu tenho que pegar e me esforçar um pouco mais, sempre pensando nela, no futuro, pra dar conta". Para ele, ser pai "é diferente, é estranho, mas isso a gente tenta se adaptar". Sentia dificuldade de conciliar a paternidade e as tarefas escolares. Inicialmente relutou em descrever-se como pai: "ah, não sei", mas depois afirmou que tentava acompanhar a filha em tudo que fosse possível, "pra saber das dificuldades dela e coisa, assim, ficar sempre do lado dela, qualquer coisa, se ela precisar, ela pode contar comigo".

\section{Primeiro Ano do Bebê}

Miguel comentou que estava se sentindo "super feliz" como pai: "eu sempre pensei que eu ia ter filho, então é uma coisa, assim, que eu queria ser, ter o pai que eи não tive, e eu acho que eu estou sendo, porque eu sempre quis, eu nunca disse que eи não queria".

Continuava achando difícil administrar os estudos, o trabalho e a paternidade. Para ele, a situação estava "bem diferente. Todo mundo no início falava que prejudicava um pouco, mas agora todo mundo tá aceitando". Descreveu-se como um pai "bem legal, eu tô sempre com ela, sempre brincando com ela, fico em volta assim".

\section{Segundo Ano do Bebê}

Miguel estava achando "legal" ser pai naquele momento, porque "cada vez que vai crescendo, parece que eles vão criando, assim, uma independência. Por um lado é bom, mas por outro, quanto mais rápido eles vão crescendo, mais rápido eles vão se distanciar da gente". Não estava sentindo nenhuma dificuldade em desempenhar o papel paterno naquele momento: "acho que é só aquele susto, aquela coisa, logo no começo, logo quando é bem pequenininha assim, que tu não sabe... Mas depois tu vai te acostumando e acaba sendo fácil, normal. Todo mundo acha que é difícil, mas não é".

Descreveu-se como um bom pai, presente, "sempre cuidando pra ela não se machucar". Disse não seguir nenhum modelo paterno, "eu acho que cada um é cada um assim. Eu sou eu, e eu vou passar assim pra ela o que eu sou". Ao mesmo tempo, não queria seguir "os pais que são chatos, que reprimem muito a criança, que não deixam a criança fazer um pouco o que ela quer". Como não conheceu seu pai, não referiu nenhuma lembrança paterna. Também disse não lembrar do relacionamento com a mãe, mas comentou que "o que eu aprendi com a mãe, eu passo assim pra ela, pra formação do caráter dela, eu acho que é isso mais que eu passo assim, que eu aprendi com a mãe". 
Separação-Individuação na Transição

para a Paternidade

Miguel inicialmente parece ter aceitado bem a paternidade, mostrando-se dedicado e participativo. Assim, ficou evidenciada a compensação da ausência paterna através de um grande envolvimento com a filha, servindo o próprio pai como um modelo a ser evitado e transformado (Colarusso, 1990; Szejer \& Stewart, 1997; E. Trindade \& Bruns, 1999), reparando sua própria história de falta (Szejer \& Stewart, 1997). Para isso, colaborou a presença de outros modelos, especialmente a mãe, com Miguel muitas vezes assumindo uma postura cuidadora, dedicando-se à casa e à filha mais do que à companheira.

Embora tenha conseguido se imaginar como pai na gestação, ancorado na imagem positiva do pai de um amigo de infância, no terceiro mês teve certa dificuldade para se definir nesse papel. O fato de Miguel desejar ter um pai apareceu em sua fala ("ser, ter o pai que nunca tive”), o que pode ter sido compensado pela busca de outros modelos e pela identificação com a filha, que pode ter lhe proporcionado uma vivência tanto ativa como passiva do cuidado parental (Colarusso, 1990).

Contudo, apesar de Miguel estar bem ciente de sua própria história, isso parece não ter significado uma maior elaboração das suas vivências de abandono, pois foi se mostrando, ao longo do tempo, menos envolvido e interessado, mais direcionado para atividades "adolescentes", como sair com os amigos. Pode-se pensar que a paternidade tenha reativado tanto o desejo de amar e ser amado, como a raiva do pai abandonante, impedindo-o de desfrutar plenamente essa condição. De qualquer modo, Miguel parece ter se lançado a uma tentativa, não de todo exitosa, de separação-individuação frente à própria figura paterna, adotando outros modelos parentais para seguir ou evitar.

\section{Caso 3: Dante}

\section{Gestação}

Segundo Dante, a gravidez, ocorrida vinte dias após ele e Ana (14 anos) "ficarem" pela primeira vez, não foi planejada. Ao saber da notícia, achou "legal, por causa que eu também queria”. Dante ficou feliz, apesar de comentar que "nós não queríamos, nós somos muito jovens também”. Imaginava que sua relação com o filho seria "das melhores". Imaginando-se como pai, se via trocando as fraldas do filho, jogando bola, fazendo-o dormir e cuidando-o: "eu imagino tudo, já, como qualquer outro pai, carinhoso, fazendo ele dormir, tudo! $O$ ruim deve ser umas três horas da manhã ele tá chorando e ter que se levantar".

Dante disse não ter um modelo de pai a ser seguido: "eu quero ser eu mesmo, eu mesmo com ele". Como modelo paterno a ser evitado, citou pais "malandros", como seus tios traficantes, que estavam distantes dos filhos. Para ele, bom pai era aquele que tinha "firmeza com o filho, saber falar com o filho, não é toda hora berrando, que não leva a nada, educar o filho. Fez alguma coisa, bota lá no quarto; se dá [surra], ele acaba morrendo de tanto apanhar!”.

Dante disse se lembrar do pai com ele quando pequeno: "o meu pai era muito bom comigo, bah, me levava pra tudo que era lugar, só bicicleta eu tive quatro, só bicicleta cara. O meu pai é muito bom comigo, até hoje ele é!". Já sobre a mãe, Dante comentou o fato de ela têlo abandonado quando pequeno, tendo sido criado pela avó paterna.

\section{Terceiro Mês do Bebê}

Nesse momento, Dante estava morando com a namorada e o filho na casa dos pais dela. Ele comentou que ser pai era um sonho, "mas vem muito rápido, cedo, eu não queria ter filho agora, cedo assim”. Referiu ter adiado todos os seus planos, mas imaginava que ser pai seria mais difícil do que estava sendo, "eu achava que ia ser ruim criar, mas tá sendo bom”. Acreditava estar se saindo bem, um pai bastante participativo e "coruja".

\section{Primeiro Ano do Bebê}

Dante comentou que "apesar de eu ser novo, está sendo bom" ser pai. Disse estar "dando mais valor aos meus pais também, que antes eu não dava muito. A gente pensava 'Ah, quem sabe sou eu!', agora não, a gente escuta mais eles". Imaginava que tudo seria mais difícil, inclusive sua relação com os pais de Ana, "mas não, correu tudo bem, graças a deus, tá dando tudo bem até hoje. Foi até bom que ele nasceu, bem legal!’.

\section{Segundo Ano do Bebê}

Dante, neste momento, referiu se sentir bem como pai, "apesar de eu ser novo, agora eu vivo pra ele! Fazer o quê? Aconteceu, né, agora tem que levar. Mas é bom, legal”. Disse não estar enfrentando nenhum tipo de dificuldade, "nem financeira, nem pessoal. Aprendi muita coisa com ele... responsabilidade, ser mais pessoa. Antes eu era muito cheio, agora aprendi a ser mais humilde".

Dante considerava que estava sendo "um ótimo pai, eu acho que eu tô bem, pela minha pouca experiência, pouca idade”. Gostava muito de passear e brincar com o filho. Não gostava de brincar de luta com ele.

Sobre o pai, comentou que "sempre foi carinhoso, a minha mãe é que eu não lembro". Além disso, referiu que o pai sempre lhe deu tudo o que precisava. Acreditava que a sua relação com ele influenciava em tudo, "educação, carinho. Eu não pretendo passar o que o meu pai me passou, que eu tinha tudo sempre, nunca batalhei por nada. Eu pretendo que o meu filho corra atrás já”.

\section{Separação-Individuação na Transição para a Paternidade \\ Dante apresentou certa ambivalência em relação à pa- ternidade, apontando o adiamento de seus planos de vida}


e o fato de ser muito jovem, mas, por outro lado, deixando transparecer o prazer que sentia no relacionamento com o filho. No segundo ano apareceu, de forma mais evidente, o amadurecimento pessoal decorrente dessa experiência.

A partir da exposição de sua história, ficou evidente que Dante teve tanto modelos paternos a serem seguidos quanto a serem evitados, o que parece tê-lo auxiliado a agir como pai (E. Trindade \& Bruns, 1999). Entretanto, apesar de ter conseguido projetar-se como pai na gravidez, provavelmente baseando-se em seu próprio pai (Colarusso, 1990), Dante não o citou como modelo, afirmando ser seu próprio modelo. Tal fato poderia estar representando um movimento de afastamento da figura paterna, na busca de maior separação-individuação (Blos, 1996), a partir da reavaliação da relação com o próprio pai (Brazelton \& Cramer, 1992; Colarusso, 1990; Costa \& Katz, 1992), na tentativa de superação de algumas de suas falhas.

De fato, ele repetiu parcialmente as atitudes paternas. Porém, a pouca convivência com o filho em alguns momentos, por motivo de trabalho, remeteu à possível influência de outros modelos (Colarusso, 1990; Szejer \& Stewart, 1997), no caso, os modelos a serem evitados que citou, bem como às lembranças de abandono materno. De qualquer modo, por ter tido contato com um modelo paterno positivo, Dante pareceu conseguir, com mais liberdade, ser como gostaria, tomando para si o que considerava positivo, afirmando não apenas diferenças, mas também semelhanças em relação ao pai (Colarusso, 1990).

\section{Discussão Geral}

Os achados do presente estudo corroboraram parcialmente a literatura, que indica que pais adolescentes, tendem a aperesentar uma relação emocional e/ou fisicamente distante com o próprio pai (Allen \& Doherty, 1996; Dallas \& Chen, 1998; E. Trindade \& Bruns, 1999). Esta situação acabaria por repercutir negativamente sobre o exercício da paternidade pelo adolescente (Allen \& Doherty, 1996). Entretanto, os modelos parentais podem ser tanto repetidos como transformados (Colarusso, 1990; Szejer \& Stewart, 1997; E. Trindade \& Bruns, 1999). Nesse sentido, um dos jovens (Dante) parece ter repetido parcialmente o modelo paterno, enquanto os outros dois (Cléber e Miguel) se tornaram pais cuidadores e presentes, diferentemente dos seus próprios pais, que foram ausentes em suas vidas. Isto sugere uma possível reflexão e transformação dessa experiência por parte destes jovens, já identificado na gestação do/a filho/a. Estes achados apóiam aqueles encontrados por Allen e Doherty (1996), de que os adolescentes muitas vezes eram melhores pais do que seus próprios pais haviam sido, confirmando, assim, a idéia de que a geração de um filho pode levar o futuro pai a se igualar ao próprio pai ou até mesmo a superá-lo (Colarusso, 1990; Costa \& Katz, 1992).
Desse modo, percebe-se que a forma como cada um se projeta como pai relaciona-se não apenas com o modelo paterno recebido, mas também com outros modelos (Szejer \& Stewart, 1997) como citado pelos participantes do presente estudo. Na verdade, especialmente Cléber e Miguel se basearam em suas mães e avós para educar/ criar o próprio filho, assumindo muitas vezes uma postura cuidadora, tradicionalmente considerada feminina (Z. A. Trindade, 1993). Conforme Brazelton e Cramer (1992), o homem, na construção de sua identidade de pai, necessita integrar duas figuras muitas vezes opostas, com as quais se identifica, no caso, a mãe e o pai. Somente uma solução equilibrada possibilitará a identificação com a gravidez da mulher e a aceitação de seu papel na criação dos filhos, tal como aconteceu com os participantes desse estudo.

Entretanto, o fato de, em alguns momentos, os três jovens haverem considerado a si mesmos como modelos paternos, pode indicar, do ponto de vista psicanalítico, um movimento de conversão da libido objetal em libido narcisista, que resultaria na autocentralização e auto-absorção do adolescente, representando a independência dos objetos amados e odiados de sua infância, em um movimento característico da segunda individuação (Blos, 1996). Presume-se que esse processo tenha sido mais difícil para os dois jovens que nem conheceram seus pais (Cléber, Miguel), pois necessitaram realizar um desligamento psíquico de um objeto ao qual não haviam concretamente se vinculado. Assim, é possível pensar que a falta de um modelo paterno de referência os levou a se assumirem como modelos, na tentativa de ser para o filho o pai que não tiveram. Além disso, tal ausência parece ter gerado uma idealização do papel paterno, à qual tentaram corresponder, pelo menos nos primeiros dois anos de vida da criança.

Os achados do presente estudo também geram um questionamento acerca da continuidade ou não desse panorama no desempenho futuro do papel paterno. Isso porque a adolescência é caracterizada como um momento de protesto e de oposição, no sentido de definição da identidade de forma contrastante à dos pais (Blos, 1996) - ao invés de uma reavaliação madura dos pontos positivos desses modelos, que é característica da idade adulta jovem (Colarusso, 1990). Contudo, de modo geral, os resultados demonstraram que os jovens pais desejavam defender os filhos contra as falhas que perceberam em suas vidas (Brazelton \& Cramer, 1992; Fraiberg, Adelson, \& Shapiro, 1983/1994). Tal fato corrobora as idéias de Goodyear, Newcomb e Allison (2000), de que a paternidade poderia ser considerada como uma tentativa de viver uma nova experiência de intimidade e criar uma família própria para amar e ser amado.

A partir dos achados do presente estudo ficou evidente que tanto a adolescência como a paternidade evocam a história pessoal dos genitores, promovendo uma reavaliação das relações (reais e fantasiadas) com os próprios pais, auxiliando na elaboração do novo papel parental. 
Tal revivência de temas e conflitos infantis gerou alguns avanços no desenvolvimento emocional dos jovens pais. Os resultados revelaram, por exemplo, a presença tanto de características da segunda individuação, esperada na adolescência - tais como a ênfase nas diferenças entre o jovem e seus pais e a oposição aos mesmos e aos seus aspectos negativos - como a busca de novos modelos de identificação, características da terceira individuação, que envolveria a consideração de aspectos positivos dos pais e da educação recebida, com o desejo de manutenção de seus acertos e a transformação de seus erros ou inadequações.

Tais resultados fazem pensar que a paternidade na adolescência, apesar de dificultar a vivência de algumas tarefas específicas da fase, como a experimentação afetiva e sexual, não traz apenas repercussões negativas, podendo também promover alguns avanços no desenvolvimento pessoal, devido ao cumprimento de tarefas de maior complexidade afetiva. Assim, ao proporcionar um novo e importante vínculo no qual o adolescente pode se ancorar durante o processo de separação emocional dos próprios pais, e ao permitir que reviva a simbiose infantil numa posição ativa na relação com o seu/sua filho/a (Colarusso, 1990), a paternidade pode auxiliar o jovem pai a preencher algumas carências afetivas e, com isso, enfrentar os lutos psíquicos da adolescência (Aberastury, 1981; Borges, 1999). Nesse sentido, o filho e/ou uma companheira poderiam contribuir para evitar a solidão decorrente do desligamento dos objetos internos na adolescência (Blos, 1996), que se soma, em alguns casos, à falta de outros vínculos (como as relações de amizade).

Por fim, não se pode deixar de comentar que, no presente estudo, a idade e o nível socioeconômico dos participantes não parecem ter interferido nessa vivência, pois inclusive o pai mais jovem e de nível socioeconômico mais baixo apresentou características da terceira individuação. Embora relevantes, esses fatores parecem não ser suficientes para explicar a complexa dinâmica envolvida na transição para a paternidade entre adolescentes. Inúmeros outros fatores (pessoais, familiares, sociais e culturais) interagem e influenciam na qualidade e na forma dessa transição. Por isso, sugere-se que novos estudos continuem a investigar os diversos aspectos da relação dos jovens pais com seu/sua filho/a, fazendo avançar ainda mais a compreensão das dimensões psicossociais desse momento marcante de vida, que têm importantes conseqüências para o próprio adolescente, mas também para o desenvolvimento do bebê.

\section{Referências}

Aberastury, A. (1981). O adolescente e a liberdade. In A. Aberastury \& M. Knobel (Eds.), Adolescência normal: Um enfoque psicanalítico (10. ed., pp. 13-23). Porto Alegre, RS: Artes Médicas.

Allen, W. D., \& Doherty, W. J. (1996). The responsibilities of fatherhood as perceived by African American teenage fathers. Families in Society: The Journal of Contemporary Human Services, 77(3), 142-155.
Bardin, L. (1977). Análise de conteúdo. Lisboa, Portugal: Edições70.

Blos, P. (1994). Adolescência: Uma interpretação psicanalítica. São Paulo, SP: Martins Fontes.

Blos, P. (1996). Transição adolescente: Questões desenvolvimentais. Porto Alegre, RS: Artes Médicas.

Borges, I. C. B. (1999). Uma delicada travessia. Cadernos Psicanalíticos, 21(13), 45-53.

Brazelton, T. B., \& Cramer, B. G. (1992). As primeiras relações. São Paulo, SP: Martins Fontes.

Chalem, E., Mitsuhiro, S. S., Ferri, C. P., Barros, M. C. M., Guinsburg, R., \& Laranjeira, R. (2007). Gravidez na adolescência: Perfil sócio-demográfico e comportamental de uma população da periferia de São Paulo, Brasil. Cadernos de Saúde Pública, 23(1), 177-186.

Colarusso, C. A. (1990). The third individuation: The effect of biological parenthood on separation-individuation processes in adulthood. Psychoanalitical Study of the Child, 45, 179-194.

Costa, G. P., \& Katz, G. (Eds.). (1992). Dinâmica das relações conjugais. Porto Alegre, RS: Artes Médicas.

Dallas, C. M., \& Chen, S. C. (1998). Experiences of African American adolescent fathers. Western Journal of Nursing Research, 20(2), 210-222.

Folle, E., \& Geib, L. T. C. (2004). Representações sociais das primíparas adolescentes sobre o cuidado materno ao recémnascido. Revista Latino-Americana de Enfermagem, 12(2), 183-190.

Fonseca, J. L. (1997). Paternidade adolescente: Uma proposta de intervenção. Dissertação de Mestrado não-publicada, Pontifícia Universidade Católica de São Paulo, SP.

Fraiberg, S., Adelson, E., \& Shapiro, V. (1994). Fantasmas no quarto do bebê: Uma abordagem psicanalítica dos problemas que entravam a relação mãe-bebê. Revista do CEAPIA, 7(7), 12-34. (Original publicado em 1983)

Grupo de Pesquisa em Infância, Desenvolvimento e Psicopatologia. (1998a). Entrevista de contato inicial. Manuscrito não-publicado, Universidade Federal do Rio Grande do Sul.

Grupo de Pesquisa em Infância, Desenvolvimento e Psicopatologia. (1998b). Entrevista de dados demográficos do casal. Manuscrito não-publicado, Universidade Federal do Rio Grande do Sul.

Grupo de Pesquisa em Infância, Desenvolvimento e Psicopatologia. (1998c). Entrevista sobre a gestação e as expectativas do futuro pai. Manuscrito não-publicado, Universidade Federal do Rio Grande do Sul.

Grupo de Pesquisa em Infância, Desenvolvimento e Psicopatologia. (1999). Entrevista sobre a experiência da paternidade: Terceiro mês do bebê. Manuscrito não-publicado, Universidade Federal do Rio Grande do Sul.

Grupo de Pesquisa em Infância, Desenvolvimento e Psicopatologia. (2000). Entrevista com o pai sobre o desenvolvimento do bebê: Primeiro ano do bebê. Manuscrito nãopublicado, Universidade Federal do Rio Grande do Sul.

Grupo de Pesquisa em Infância, Desenvolvimento e Psicopatologia. (2001). Entrevista com o pai sobre o desenvolvimento do bebê: Segundo ano do bebê. Manuscrito nãopublicado, Universidade Federal do Rio Grande do Sul.

Goodyear, R. K., Newcomb, M. D., \& Allison, R. D. (2000). Predictors of Latino men's paternity in teen pregnancy: Test of a mediational model of childhood experiences, gender role attitudes, and behaviors. Journal of Counseling Psychology, 47(1), 116-128. 
Instituto Brasileiro de Geografia e Estatística. (2005). Estatísticas do Registro Civil, 32. Retrieved September 20, 2007, from http://www.ibge.gov.br/home/estatistica/populacao/ registrocivil/2005/registrocivil_2005.pdf

Laville, C., \& Dionne, J. (1999). A construção do saber: Manual de metodologia de pesquisa em Ciências Humanas. Porto Alegre, RS: Artes Médicas.

Levandowski, D. C. (2001). Paternidade na adolescência: Expectativas, sentimentos e a interação com o bebê. Dissertação de Mestrado não-publicada, Universidade Federal do Rio Grande do Sul, Porto Alegre, RS.

Levandowski, D. C. (2005). A transição para a parentalidade e a relação de casal de adolescentes. Tese de Doutorado não-publicada, Universidade Federal do Rio Grande do Sul, Porto Alegre, RS.

Levandowski, D. C., \& Piccinini, C. A. (2002). A interação pai-bebê entre pais adolescentes e adultos. Psicologia: Reflexão e Crítica, 15(2), 413-424.

Levandowski, D. C., \& Piccinini, C. A. (2004). Paternidade na adolescência: Aspectos teóricos e empíricos. Revista Brasileira de Crescimento e Desenvolvimento Humano, 14(1), 51-67.

Levandowski, D. C., \& Piccinini, C. A. (2006). Expectativas e sentimentos em relação à paternidade entre adolescentes e adultos. Psicologia: Teoria e Pesquisa, 22(1), 17-27.

Levandowski, D. C., Piccinini, C. A., \& Lopes, R. S. (no prelo). Individualidade e conjugalidade na relação de casal de adolescentes. Psicologia em Estudo, 14(3).

Magalhães, M. L. C., Furtado, F. M., Nogueira, M. B., Carvalho, F. H. C., Almeida, F. M. L., Mattar, R., et al. (2006). Gestação na adolescência precoce e tardia: Há diferença nos riscos obstétricos? Revista Brasileira de Ginecologia e Obstetrícia, 28(8), 446-452.

Mahler, M. (1982). O processo de separação-individuação. Porto Alegre, RS: Artes Médicas.

Mahler, M. S., Pine, F., \& Bergman, A. (2002). O nascimento psicológico da criança: Simbiose e individuação. Porto Alegre, RS: ArtMed.

McCallum, C., \& Reis, A. P. (2006). Re-significando a dor e superando a solidão: Experiências do parto entre adolescentes de classes populares atendidas em uma maternidade pública de Salvador, Bahia, Brasil. Cadernos de Saúde Pública, 22(7), 1483-1491.

Medrado, B., \& Lyra, J. (1999). A adolescência "desprevenida" e a paternidade na adolescência: Uma abordagem geracional e de gênero. In N. Schor, M. S. F. T. Mota, \& V. Castelo Branco (Eds.), Cadernos juventude, saúde e desenvolvimento (Vol. 1, pp. 230-248). Brasília, DF: Ministério da Saúde.

Piccinini, C. A., Tudge, J., Lopes, R. S., \& Sperb, T. M. (1998). Estudo longitudinal de Porto Alegre: Da gestação à escola. Manuscrito não-publicado, Universidade Federal do Rio Grande do Sul.

Silva, D. V., \& Salomão, N. M. R. (2003). A maternidade na perspectiva de mães adolescentes e avós maternas dos bebês. Estudos de Psicologia (Natal), 8(1), 135-145.

Stake, R. E. (1994). Case studies. In N. Denzin, \& Y. Lincoln (Ed.), Handbook of qualitative research (pp. 236-247). London: Sage.

Szejer, M., \& Stewart, R. (1997). Nove meses na vida da mulher: Uma abordagem psicanalítica da gravidez e do nascimento. São Paulo, SP: Casa do Psicólogo.
Trindade, E., \& Bruns, M. A. T. (1999). Adolescentes e paternidade: Um enfoque fenomenológico. Ribeirão Preto, SP: Holos.

Trindade, Z. A. (1993). As representações sociais e o cotidiano: A questão da maternidade e da paternidade. Psicologia: Teoria e Pesquisa, 9(3), 535-546.

Trindade, Z. A., \& Menandro, M. C. S. (2002). Pais adolescentes: Vivência e significação. Estudos de Psicologia (Natal), 7(1), 15-23.
Recebido: 04/10/2007

$1^{a}$ revisão: 03/03/2008

$2^{a}$ revisão: 04/06/2008 Aceite final: 09/07/2008 